\title{
Knowledge, Attitude and Practices of Undergraduate Medical and Nursing Students Regarding Basic Life Support Training
}

\author{
Omar Nisar $^{1 *}$, Sameet Ahmad ${ }^{1}$, Rida Tariq ${ }^{1}$, Muneeba Arif ${ }^{1}$, Sana Waheed ${ }^{1}$ and Samaha Nisar ${ }^{1}$
}

\begin{abstract}
Objective: To assess and compare the Knowledge, Attitude, and Practices of Medical and Nursing Students regarding Basic Life Support Training

Methodology: This cross-sectional study was done at the Shalamar Institute of Health Sciences, Lahore in a period of three months. Students from all years of MBBS and BS Nursing were taken as subjects. Participants satisfying inclusion criteria were requested to fill out a self-structured pre-tested questionnaire after informed consent. Data was analyzed using SPSS v.21.

Results: There were 330 participants from MBBS and BS Nursing (50 from each class of MBBS and 20 from each class of BS Nursing). The age of participants ranged from 18 to 30 (Figure 1). Only 250 subjects had heard about BLS. Out of 330 participants, only 204 had good knowledge about BLS (Table 2) and 126 had poor knowledge of BLS where score of higher than 3 out of 7 was considered as good. Knowledge of Medical and Nursing students was compared and the $p$-value came out to be 0.088 , which was considered insignificant. Only $34.5 \%$ of the participants had learned BLS by training and only $13.3 \%$ of the participants (Table 3 ) had practically done BLS. Most of the people gave no reason for not attending a training session for BLS. Conclusion: It was concluded that medical and nursing students had satisfactory knowledge of BLS and more attention was needed towards this important life-saving skill.
\end{abstract}

Key words: Cardiopulmonary Resuscitation, Medical, Undergraduate, Knowledge, Attitude, Practices, Nursing

How to cite this article: Nisar O, Ahmad S, Tariq R, Arif M, Waheed S, Nisar S. Knowledge, attitude and practices of undergraduate medical and nursing students regarding basic life support training. Ann Jinnah Sindh Med Uni 2020; 6(2):60-65

DOI: https://doi.org/10.46663/ajsmu.v6i2.60-65

\section{INTRODUCTION}

Basic Life Support is a set of life-saving techniques like cardiopulmonary resuscitation (CPR) and basic airway management ${ }^{1}$. The matter at hand is the Knowledge, Attitude and Practices of medical and nursing students related to this crucial aspect of the field that is Basic Life Support (BLS). Cardiac Emergencies are one of the most common emergencies seen in the ERs of any hospital. BLS can increase the chances of survival of patients in such emergencies ${ }^{2}$.

Medical students in Pakistan lack cognitive awareness though they consider it to be an important part of curriculum $^{3}$. As medical students and nurses lack knowledge of BLS, attention needs to be paid to teaching it and providing opportunities to students for hands-on practice of BLS where possible ${ }^{4}$.

1 Shalamar Medical and Dental College, Shalamr Link Road, Mughalpura, Lahore, Pakistan

Correspondence: Omar Nisar*, Shalamar Medical and Dental College, Shalamr Link Road, Mughalpura, Lahore, Pakistan

Email: mbbs2016101@student.smdc.edu.pk
BLS has not yet played a significant role in the care of a critical patient as it should have mainly because of a lack of resources and awareness among students. Other than that, those students who have been trained, do not adequately exercise their skills during emergencies and teach their expertise to the younger generation of doctors and nurses ${ }^{5}$. The discussion about high-risk patients and the benefit they can get through proper Basic Life Support measures and training is an eye-opener and also gives the idea about how it is essential for non-risk patients as well. A study conducted on the eligible patients showed the BLS resulted in a $27 \%$ decrease in cardiac arrests, a $33 \%$ decrease in deaths due to cardiac arrests, and a $17 \%$ decrease in overall in-hospital deaths ${ }^{6}$. One can only imagine how these percentages can be increased by implementing the knowledge on Basic Life Support and conducting continuous feedback to make it better at every step. Proper administration of first aid and resuscitation is essential following extreme conditions of shock and cardiac arrest. But unfortunately, our medical and nursing students are not familiar enough with the 
training of Basic Life Support despite the fact that they are studying to become medical professionals. The focus needs to be on the skills and techniques which make BLS effective. There needs to be a balance between confidence and competence of the health workers in order to address this inadequacy ${ }^{7}$.

The objective of this study was to comprehend and evaluate the attitude of doctors and nurses towards Basic Life Support. Only that way an ideal and improved plan can be designed and initiated. The setbacks to accurate CPR administration and emergency ABC protocols must be tackled after the current situation and educational status about BLS should be recognized. Even though, the topic is less common to be discussed but as far as its importance is concerned, it should be given more attention. In addition to the medical personnel, the friends, and family members of high-risk patients should be trained too. BLS training must be given to every person medical or non-medical provided they are willing and competent ${ }^{8}$.

\section{METHODOLOGY}

It was a cross-sectional study conducted in Shalamar Institute of Health Sciences, Lahore. MBBS and BS Nursing students were the target population. The duration of the study was three months. Sociodemographic variables and Knowledge, Attitude and Practices of BLS were the variables. Students of MBBS Year 1-5 and BS Nursing Year 14 willing to be a participant of this study were included. Students who were repeating the session were excluded. Students from courses other than MBBS and BS Nursing were excluded. Students not consenting to the study were excluded.

Our target population was MBBS and BS Nursing students of the undergraduate level of Shalamar Institute of Health Sciences. The minimum calculated sample size using Open Epi Version 3 was 274 with Confidence Level of $95 \%$ and Margin of Error 5\%. We took 330 students, out of whom 250 students were from MBBS (50 each from $1^{\text {st }}, 2^{\text {nd }}, 3^{\text {rd }}, 4^{\text {th }}$ and final year) and 80 were from BS Nursing (20 from each year) with a non-response margin of $17 \%$.

The data was collected by circulating self-structured pre-tested printed questionnaire (Annex-1) developed from American Heart Association Basic Life Support Guidelines 2016, among the students in person and also through Google Forms.

Participants were approached and after taking informed consent, they were given the questionnaire(Annex-1). Participants then returned the questionnaire to the researchers. The data was also collected online through Google Forms. Before filling an online form, informed consent from the participants was taken. Statistical analysis was performed using SPSS version 21. The knowledge, attitude and practices of participants were assessed through a 14-item questionnaire. Every correct answer was awarded 1 point making a maximum score 7 (for knowledge related questions). Chi-square and Fisher's Exact Test was applied in which a p-value of less than 0.05 is considered significant.

Ethical approval was obtained from the college IRB committee (letter reference number SMDC/IRB/0807/181).

\section{RESULTS}

The data was collected from 330 participants including students from both MBBS and BS Nursing. The age range of participants was from 18 years to 30 years (Figure I). The participants were from 1st Year of MBBS till the Final Year of MBBS and from 1st Year till 4th Year of BS Nursing. Females enrolled were $53.03 \%$. p value of less than 0.05 was considered significant.

The Knowledge was tested using seven questions and the frequencies and percentages of each option are mentioned with the $\mathrm{p}$ value for each question in Table 1. The Knowledge score was calculated for each of the participants out of seven and a score of lesser than or equal to three was considered as having poor knowledge while a score of greater than three was considered as good knowledge. The results are crosstabulated in Table-2. Chi-Square and Fisher's Exact Test was applied to find out the association of MBBS and BS Nursing Class to Knowledge about BLS and to compare the knowledge and p-value were calculated which came out to be 0.088 which was considered as statistically insignificant.

Furthermore, the attitude and practices of participants was also tested using various questions and the frequency of each answer is given in Table 3. Out of the 330 students, 250 had heard of BLS, while 80 had never heard of BLS. More MBBS students had heard about BLS than BS Nursing (Table 3). As many as 114 (34.5\%) participants had learned about BLS by attending a training session while $216(65.5 \%)$ had not attended a training session.

No particular reason was given by 100 (30.3\%) participants for not attending a training session while others stated lack of opportunities, laziness and being busy with their studies as their reasons (Table 4). 
Table 1: Answers of Questions about Knowledge of BLS and the Frequencies and Percentages of Each Option

\begin{tabular}{|c|c|c|c|c|c|}
\hline Question & \multicolumn{2}{|c|}{$\operatorname{MBBS}(\mathbf{N}=\mathbf{2 5 0})$} & \multicolumn{2}{|c|}{ BS Nursing (N=80) } & \multirow[t]{2}{*}{ P value } \\
\hline \multirow{6}{*}{$\begin{array}{l}\text { Who should be trained in BLS? } \\
\text { Citizens } \\
\text { Doctors } \\
\text { Hospital Staff } \\
\text { Nurses } \\
\text { All of the above }\end{array}$} & Frequency & Percentage & Frequency & Percentage & \\
\hline & 12 & 4.8 & 3 & 3.8 & \multirow{5}{*}{0.349} \\
\hline & 12 & 4.8 & 4 & 5.0 & \\
\hline & 4 & 1.6 & 4 & 5.0 & \\
\hline & 1 & 0.4 & 1 & 1.3 & \\
\hline & 221 & 88.4 & 68 & 85.0 & \\
\hline \multicolumn{6}{|l|}{ Where BLS measures can be performed? } \\
\hline ICU only & 4 & 1.6 & 1 & 1.3 & \\
\hline Hospital only & 23 & 9.2 & 10 & 12.5 & \\
\hline Anywhere & 216 & 86.4 & 67 & 83.8 & 0.792 \\
\hline Cardiac Ward Only & 4 & 1.6 & 2 & 2.5 & \\
\hline Others & 3 & 1.2 & 0 & 0 & \\
\hline \multicolumn{6}{|l|}{ Where hands of BLS performer are to be } \\
\hline Below Clavicle & 22 & 8.8 & 12 & 15 & \\
\hline Upper Half of Sternum & 90 & 36.0 & 25 & 31.3 & \\
\hline Lower Half of Sternum & 90 & 36.0 & 21 & 26.3 & 0.972 \\
\hline Xiphisternum & 39 & 15.6 & 20 & 25 & \\
\hline Others & 9 & 3.6 & 2 & 2.5 & \\
\hline \multicolumn{6}{|l|}{$\begin{array}{l}\text { What is the number of chest compressions } \\
\text { in adults? }\end{array}$} \\
\hline 12 & 27 & 10.8 & 2 & 2.5 & \\
\hline 20 & 66 & 26.4 & 18 & 22.5 & 0.003 \\
\hline 25 & 67 & 26.8 & 17 & 21.3 & \\
\hline $100-120$ & 90 & 36.0 & 43 & 53.8 & \\
\hline \multicolumn{6}{|l|}{$\begin{array}{l}\text { How deep chest compressions should be } \\
\text { in adults? }\end{array}$} \\
\hline 2 inches & 77 & 30.8 & 39 & 48.8 & \\
\hline 1.5 inches & 97 & 38.8 & 17 & 21.3 & 0.263 \\
\hline 5 inches & 29 & 11.6 & 7 & 8.8 & \\
\hline 2.5 inches & 47 & 18.8 & 17 & 21.3 & \\
\hline \multicolumn{6}{|l|}{$\begin{array}{l}\text { What is chest compression to breath ratio } \\
\text { in adults? }\end{array}$} \\
\hline $30: 2$ & 120 & 48 & 50 & 62.5 & \\
\hline $30: 4$ & 52 & 20.8 & 4 & 5.0 & 0.871 \\
\hline $15: 3$ & 65 & 26.0 & 13 & 16.3 & \\
\hline $5: 2$ & 13 & 5.2 & 13 & 16.3 & \\
\hline $\begin{array}{l}\text { Are emergency medicines required for BLS? } \\
\text { Yes } \\
\text { No }\end{array}$ & $\begin{array}{l}106 \\
144\end{array}$ & $\begin{array}{l}42.4 \\
57.6\end{array}$ & $\begin{array}{l}33 \\
47\end{array}$ & $\begin{array}{l}41.3 \\
58.8\end{array}$ & 0.857 \\
\hline
\end{tabular}




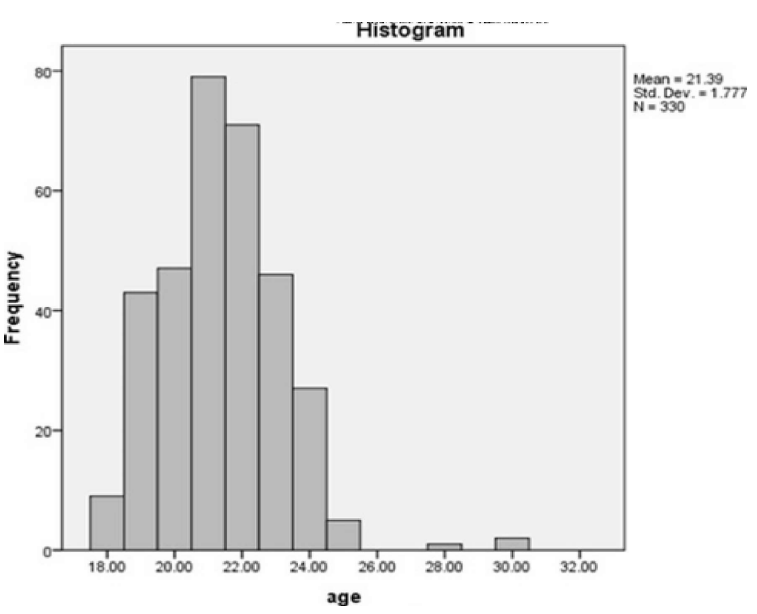

Figure 1: Age of the Participants

Table 2: Cross Tabulation for MBBS and BS Nursing Student Divided as Poor Knowledge and Good Knowledge

\begin{tabular}{|l|c|c|}
\hline & $\begin{array}{c}\text { Poor Knowledge } \\
\text { (Lesser than } \\
\text { or Equal to 3) }\end{array}$ & $\begin{array}{c}\text { Good Knowledge } \\
\text { (Greater than 3) }\end{array}$ \\
\hline MBBS & 102 & 148 \\
BS Nursing & 24 & 56 \\
Count & 126 & 204 \\
\hline
\end{tabular}

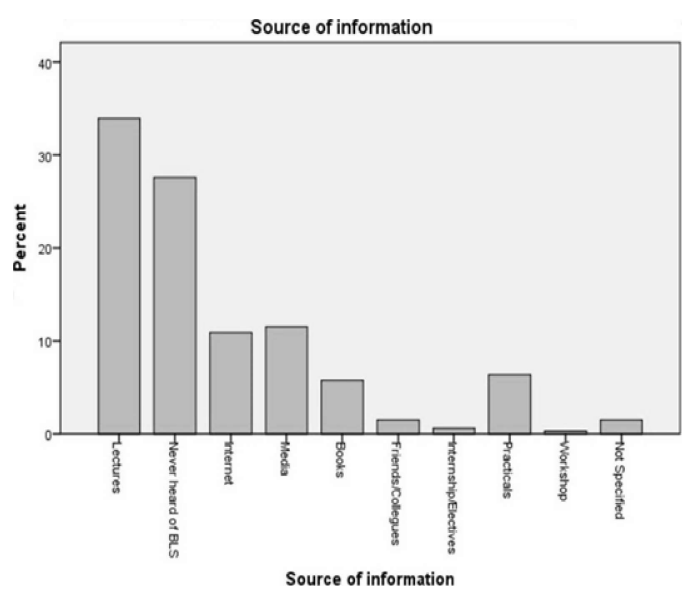

Figure 2 : Source of Information about BLS

Table 4: Reasons for No Training of BLS

\begin{tabular}{|l|c|c|}
\hline & Frequency & Percentage \\
\hline Learned BLS in training session & 126 & 38.2 \\
\hline No reason is given & 100 & 30.3 \\
\hline No opportunity was given & 95 & 28.8 \\
\hline Laziness & 1 & 0.3 \\
\hline Busy & 1 & 0.3 \\
\hline No knowledge about BLS & 7 & 2.1 \\
\hline Total & 330 & 100.0 \\
\hline
\end{tabular}

Table 3: Questions Regarding Attitudes and Practices of BLS and Frequencies and Percentages of Each Answer

\begin{tabular}{|c|c|c|c|c|c|}
\hline Question & \multicolumn{2}{|c|}{$\operatorname{MBBS}(\mathrm{N}=250)$} & \multicolumn{2}{|c|}{ BS Nursing $(\mathrm{N}=80)$} & $P$ value \\
\hline Have you ever heard about & Frequency & Percentage & Frequency & Percentage & \\
\hline Basic life support (BLS)? & & & & & \\
\hline Yes & 179 & 71.6 & 71 & 88.8 & \\
\hline No & 71 & 28.4 & 9 & 11.3 & 0.002 \\
\hline $\begin{array}{l}\text { Have you learned BLS in } \\
\text { training session? }\end{array}$ & & & & & \\
\hline Yes & 67 & 26.8 & 47 & 58.8 & \\
\hline No & 183 & 73.2 & 33 & 41.3 & $<0.001$ \\
\hline $\begin{array}{l}\text { Have you ever practically } \\
\text { ever done BLS in adults? }\end{array}$ & & & & & \\
\hline Yes & 31 & 12.4 & 13 & 16.3 & \\
\hline No & 219 & 87.6 & 67 & 83.8 & 0.379 \\
\hline $\begin{array}{l}\text { Will you perform mouth to mouth } \\
\text { breathing to an unknown person? }\end{array}$ & & & & & \\
\hline Yes & 152 & 60.8 & 33 & 41.3 & \\
\hline No & 98 & 39.2 & 42 & 52.5 & 0.036 \\
\hline $\begin{array}{l}\text { In your opinion, should BLS be included } \\
\text { early in syllabi of MBBS and BS Nursing } \\
\text { along with periodic assessments? }\end{array}$ & & & & & \\
\hline Yes & 222 & 88.4 & 75 & 93.8 & \\
\hline No & 28 & 11.2 & 5 & 6.3 & 0.200 \\
\hline
\end{tabular}




\section{DISCUSSION}

Our institute Shalamar Medical and Dental College, is admitting 150 medical and 50 nursing students annually. Our college has progressively been taking steps to produce good doctors through exercises like problem-based learning, encouraging the culture of research in early years and holding trainings like BLS which are essential to produce good doctors. Our study was done among undergraduate Medical and Nursing students to assess and compare their Knowledge, Attitude and Practices about BLS. This is a unique study that compared the Knowledge, Attitude and Practices of Medical and Nursing Students which has been done previously in very few studies and emphasizes about importance of BLS training in Undergraduate Medical and Nursing curriculum. We found out that BLS was not being given its due importance. It was alarming to see that medical and nursing students who would become healthcare professionals coming directly in contact with patients, had the least knowledge and only $34.4 \%$ of participants had attended a training session for such an important skill. This indicated the need for making this training compulsory for every student studying to become a healthcare professional.

Our study showed that $81 \%$ of participants had heard about BLS while a study done in Saudi Arabia showed $93.8 \%$ of the participants had heard about BLS ${ }^{9}$. The reason for this can be that the study was done on healthcare interns and we did our study on undergraduate students and there is a gap of knowledge among pre-clinical and clinical students due to different class levels. It can also be due to the fact that BLS training is not a mandatory skill to be learnt by the undergraduates or interns in Pakistan.

A study done in Karachi showed $90.9 \%$ of the people knew that BLS can be performed anywhere while our study showed $85.8 \%$ of the people knew this ${ }^{10}$. This gap was perhaps due to a lack of training sessions and workshops and neglecting BLS in our institute and because this study was done on House Officers, Medical Officers and other senior faculty.

Our study revealed that $34.5 \%$ of the people had attended workshops while a study done in Allama Iqbal Medical College; Lahore showed only $24.3 \%$ had attended a workshop ${ }^{11}$. This might be due to practical classes for BLS held in our institute and due to a workshop given which was attended by only a few of the participants. Our study also showed that $38.18 \%$ of the people had poor knowledge about BLS while another study done in Karachi showed $22.8 \%$ which might be due to the same reason as cited above ${ }^{9}$.
Our study showed $90 \%$ of the participants thought that BLS training should be included as a compulsory part of the curriculum while another study done in India showed that $98 \%$ of the participants thought that BLS should be incorporated as an integral part of the curriculum $^{12}$. This is probably due to the reason that there is increased awareness about importance of BLS in the early years in Indian Medical and Nursing Institutes.

\section{CONCLUSION}

It was concluded that medical and nursing students had less than satisfactory knowledge of BLS and more attention was needed towards this important life-saving skill. Moreover, it was felt that training sessions should be arranged more often to teach BLS which should be made compulsory to attend for all medical and nursing students so that more students can benefit from it. This can save countless lives.

Acknowledgement: We will like to acknowledge the support of Col. Dr. Jamal Abdul Nasir (Senior Demonstrator Department of Community Medicine, Shalamar Medical and Dental College, Lahore), Professor Dr. Tahseen Haider Kazmi (Head of Department, Department of Community Medicine, Shalamar Medical and Dental College, Lahore) Maj.(R) Dr. Saadia Shahzad (Assistant Professor Department of Community Medicine, Shalamar Medical and Dental College, Lahore), Ms. Sana Naz (Statistician, Shalamar Medical and Dental College, Lahore) and Sharjeel Mahmood (Medical Student, 4th Year MBBS, Shalamar Medical and Dental College, Lahore).

Authors' contribution: ON conceptualized the study, developed questionnaire, worked on data entry and interpretation, wrote results and discussion. SA participated in data collection and entry, wrote introduction and reviewed the manuscript. RT collected and entered data, wrote the discussion. MA helped in literature search, data entry and revision. SN worked on data collection, analysis, revision and referencing.

\section{References}

1. Sangamesh NC, Vidya KC, Pathi J, Singh A. Awareness, Attitude, and Knowledge ofBasic Life Support among Medical, Dental, and Nursing Faculties and Students in the University Hospital. J Int Soc Prev Community Dent. 2017; 7(4):161-167. doi:10.4103/jispcd. JISPCD $240 \_17$.

2. Almesned A, Almeman A, Alakhtar AM, AlAboudi AA, Alotaibi AZ, AlGhasham YA,et.al. Basic life support knowledge of healthcare students and professionals in the Qassim University. Int J Health Sci (Qassim).2014; 8(2):141-150. doi: 10.12816/0006080. 
3. Zaheer H, Haque Z. Awareness about BLS (CPR) among medical students: status and requirements. J Pak Med Assoc. 2009; 59(1): 57-59.

4. Robak O, Kulnig J, Sterz F, Uray T, Haugk M, Kliegel A. et.al. CPR in medical schools: learning by teaching BLS to sudden cardiac death survivors--a promising strategy for medical students?. BMC Med Educ. 2006; 6: 27. doi:10.1186/1472- 6920-6-27.

5. Spooner BB, Fallaha JF, Kocierz L, Smith CM, Smith S, Perkins G. An evaluation of objective feedback in basic life support (BLS) training. Resuscitation. 2007;73(3):417-424. doi: 10.1016/j. resuscitation. 2006.10.017.

6. Campello G, Granja C, Carvalho F, Dias C, Azevedo L, Costa-Pereira A. Immediate and long-term impact of medical emergency teams on cardiac arrest prevalence and mortality: A plea for periodic basic life-support training programs. Crit Care Med. 2009;37(12):30543061. doi:10.1097/CCM.0b013e3181b02183.

7. Castle N, Garton H, Kenward G. Confidence vs competence: basic life support skills of health professionals. Br J Nurs.2007;16(11):664-666. doi:10. 12968/bjon.2007.16.11.23685.
8. Flint L, Billi E, Kelly K, Mandel L, Newell L, Stapleton E. Education in adult basic life support training programs. Ann Emerg Med. 1993;22(2):468-474. doi: 10.1016/ s0196-0644(05)80479-2.

9. Saquib S, Al-Harthi H, Khoshhal A, Shaher A, AlShammari A, Khan A, et al. Knowledge and Attitude about Basic Life Support and Emergency Medical Services amongst Healthcare Interns in University Hospitals: A Cross-Sectional Study. Emerg Med Int. 2019; 2019: 9342892. doi: 10.1155/2019/9342892.

10. Majid A, Jamali M, Ashrafi M, Ul Haq Z, Irfan R, Rehan A. et al. Knowledge and Attitude Towards Cardiopulmonary Resuscitation Among Doctors of a Tertiary Care Hospital in Karachi. Cureus.2019; 11(3): 4182. doi: 10.7759/cureus.4182.

11. Sohail CS, Ahmad MQ, Nadeem F, Jahngir MU, Khalil MJ, et al. Basic Life Support: Knowledge and Attitude of Medical Students. Ann Community Med Pract.2018; 4(2):1034.

12. Yunus M, Mishra A, Karim H, Raphael V, Ahmed G, Myrthong C. Knowledge, attitude and practice of basic life support among junior doctors and students in a tertiary care medical institute.Int J Res Med Sci. 2015; 3(12):3644-3650. DOI: 10.18203/2320-6012. ijrms20151416 